\section{Activity and involuntary memory: A failure to replicate*}

\author{
JOHN A. MEACHAM \\ University of Michigan, Ann Arbor, Mich, 48104
}

Forty-five Ss viewed an array of 16 words printed on cards. As each card was illuminated, $\mathbf{S}$ said the word aloud. In Condition $1, S$ also removed six cards whose positions were pointed to by $\mathrm{E}$. In Condition $2, \mathrm{~S}$ removed 6 words beginning with the letter "s." After $15 \mathrm{~min}$, Ss recalled more words in Condition 2 than in Condition 1 and a greater than chance number of positions in both conditions. Although these procedures of Leont'ev \& Rozanova (1957) were closely followed, their results could not be confirmed. Leont'ev and Rozanova were investigating involuntary memory (incidental learning) as a function of S's activity and instructions intended to activate the second signal system.

Smirnov \& Zinchenko (1969), in a recent review of Soviet research related to memory, emphasize the importance of the S's activity in determining which materials can be involuntarily (incidentally) remembered. They conclude that material which is incorporated within an activity can be remembered better than material which is related to conditions necessary for carrying out an activity. The results of an investigation by Leont'ev \& Rozanova (1957), in which Ss engaged in various activities with a fixed set of stimulus words, are cited in support of this conclusion. Leont'ev and Rozanova suggest that their results are due to instructions which, in some conditions, activated associations of the second signal system. They presented each S ("adult Ss, all of whom had received a higher education") with a 4 by 4 array of 16 cards, on each of which a common word was printed. The array was presented in a darkened room, and each card was illuminated for 2 sec. The $\mathbf{S}$ was instructed to say each word aloud and to remove certain cards. In Condition $1(N=5)$, as the cards were illuminated, $\mathrm{E}$ pointed to 6 cards which $\mathbf{S}$ was to remove. In Condition 2 $(N=10)$, the cue for removal of cards was the letter "s" at the beginning of 6 of the words. After $15 \mathrm{~min}$ of conversation, $\mathrm{S}$ was asked to recall as many of the words as possible and to point to the positions from which cards had been removed. All Ss later reported that they had not expected to be asked to recall the words or positions. In Condition 1 , Ss were unable to remember any of the words, their initial letters, or the positions from which they had removed cards. In Condition 2, however, Ss remembered an average of 1 out of 16

*The advice of Dr. D. Birch is gratefully ack nowledged. of the words and correctly identified 5.5 out of 6 of the positions. Leont'ev and Rozanova repeated this experiment and obtained similar results with words presented in a $6 \times 6$ array $(N=10)$. The following investigation was carried out in an attempt to confirm and further extend these results.

The procedures outlined by Leont'ev \& Rozanova (1957) were $45 \mathrm{Ss}$ from the introductory psychology $S$ pool was assigned to one of three experimental conditions as he arrived, the only restriction being that 8 males and 7 females be in each group. Two additional Ss were unable to complete the task appropriately and were not included. The 16 stimulus words were typed in capital letters on $2^{1 / 2} \times 3$ in. cards, and these were arranged in a 4 by 4 array on a screen approximately $18 \mathrm{in.}$ square. This screen was placed horizontally on a table in front of $S$, who sat in a completely darkened experimental booth. As a light below each of the cards was illuminated, each word was exposed for 2 sec with no interstimulus interval, proceeding from left to right within each row and from the farthest to the nearest rows. Because of the requirement that certain of the words begin with the same letter, English equivalents of the common four-letter Russian words used by Leont'ev and Rozanova could not be employed. Common words were chosen at random from the Thorndike \& Lorge (1944) list of 1,000 words occurring most frequently and were presented in the following order: hour, sign, wind, book, ship, city, bear, work, coal, snow, hole, spot, seat, wood, suit, boat. The various positions of the five initial letters corresponded to those in the array of Russian words presented by Leont'ev and Rozanova.

In all three experimental conditions, followed as closely as possible. Each of
$S$ said each of the 16 words aloud and removed six of the cards. The first two conditions were identical to those of Leont'ev \& Rozanova (1957). In Condition 1, E pointed to the 2nd, $4 \mathrm{th}, 7 \mathrm{th}, 9 \mathrm{th}, 12 \mathrm{th}$, and 15 th cards as these were illuminated, and these were immediately removed by $S$. In Condition 2, $\mathrm{S}$ was told to remove words beginning with the letter "s." Since these conditions differed both with respect to whether the cue for removal involved the second signal system, as Leont'ev and Rozanova suggest, and also with respect to whether $\mathrm{E}$ or $\mathrm{S}$ made the decision to remove a card, a third condition was added. In Condition 3 , the same cards which were removed in Condition 1 were illuminated by a light slightly different in hue from that which illuminated the remaining 10 cards. The Ss were asked to "remove the cards which are illuminated by a light which appears different from the light illuminating the first card." Thus, in Condition 3 , the cue for removal did not involve the second signal system, as in Condition 2, and $\mathrm{E}$ did not make the decision regarding removal, as in Condition 1. In all three conditions, $S$ was required to repeat the instructions back to $E$ and misunderstandings were corrected before the stimuli were exposed.

Following exposure of the stimulus words, $E$ and $S$ engaged in conversation for $15 \mathrm{~min}$. The questions employed by Leont'ev \& Rozanova (1957) were then used in asking $\mathrm{S}$ to remember the initial letters of the words, the words that were removed, words beginning with "s," and words beginning with other letters. Ss then pointed to an array of blank cards to indicate the positions of cards which they had removed. Two to three minutes were required as Ss attempted to recall the answers to these questions. Later questioning revealed that no $S$ had suspected that the experiment would involve recall of the words or positions.

RESULTS AND DISCUSSION

The results are presented in Table 1 . The mean number of words recalled was different from zero in Condition 1 $(\mathrm{t}=8.41, \mathrm{df}=14, \mathrm{p}<.001)$ and different from 1 out of 16 in Condition $2(t=5.90, d f=14$, $p<.001)$. The mean number of positions correctly identified was greater than chance $(=2.25)$ in both Condition $1(t=3.21$, df $=14$, $p<.01)$ and Condition $2(t=3.56$, df $=14, p<.01$ ) and, in contrast to the Soviet finding, was less than 5.5 out of 6 in Condition $2 \quad(t=10.57$ $\mathrm{df}=14, \quad \mathrm{p}<.001)$. As shown in Table 1 , Ss also remembered many of the initial letters of the words in both conditions. These results were 
Table 1

Means and Standard Deviations of Initial Letters, Words, and Positions Correctly Recalled



consistent with those of an earlier pilot study in which 12 words were presented on an oval array, but they did not replicate the findings reported by Leont'ev \& Rozanova (1957).

An analysis of the total number of words recalled in the three conditions of the present study revealed a significant effect of conditions $(\mathrm{F}=6.62, \mathrm{df}=2 / 42, \mathrm{p}<.01)$, with Scheffé a posteriori tests at the .05 level indicating that more words were recalled in Condition 2 than in Conditions 1 or 3. In particular, more words starting with "s" were recalled in Condition 2 than in the other two conditions $(F=11.65, \quad d f=2 / 42$, $p<.05)$. There was an effect of condition upon the mean number of initial letters recalled $(F=4.41$, df $=2 / 42, \quad p<.05$ ), but a posteriori tests showed that only the difference between Conditions 1 and 2 was significant. This increased recall of letters and words was not due to familiarity with the letter "s" and its availability as a retrieval cue, for all but three Ss in Condition 1 and one in Condition 3 recalled that "s" was an initial letter. The effects can be attributed to the instructions in Condition 2, which instigated orienting activities toward the initial letters of the words. Such instructions appear to be more important than was made by $E$ (as in Condition 1) or by $S$ (Condition 3 ). The effect of conditions upon the number of positions correctly identified was not significant, nor were there significant sex differences in the number of words or positions recalled, nor were there number of words and positions recalled.

In conclusion, the fact that differences were found between the various experimental conditions does support the hypothesis that whether the decision to remove cards significant correlations between the involuntary memory can be dependent upon the orienting activity of the $S$. The present experimental paradigm, in which findings can be expressed as a function of the S's activity rather than in terms of stimulus parameters, may be a conceptually useful means of further investigating this hypothesis. The failure of the present investigation to replicate the results of Leont'ev \& Rozanova (1957), however, suggests that those findings may not be generalizable across such variables as $\mathbf{S}$ population, testing circumstances, or perhaps the set which the $\mathbf{S}$ brings to the experimental situation. The specific source of the differences between the Soviet results and the present study has not yet been identified.

\section{REFERENCES}

LEONT'EV, A. N \& ROZANOVA, T, V . The formation of associative connections: An experimental investigation. In $B$. Simon (Ed.), Psychology in the Soviet Union. London: Routledge \& Kegan Paul, 1957.

SMIRNOV, A. A., \& ZINCHENKO, P. I. Problems in the psychology of memory. In M. Cole and I. Maltzman (Eds.), $A$ handbook of contemporary Soviet psychology. New York: Basic Books, 1969.

THORNDIKE, E. L., \& LORGE, I. The teacher's word book of 30,000 words. New Yok: Bureau of Publications, Teachers College, Columbia University, 1944. 